\title{
The post-lockdown period should be used to acquire effective therapies for future resurgence in SARS-Cov-2 infections
}

\author{
Kurt L Krause, Richard Furneaux, Paul Benjes, Margaret Brimble, \\ Tony Davidson, William Denny, Lawrence Harris, Simon Hinkley, \\ Peter Tyler, James E Ussher, Vernon Ward
}

\begin{abstract}
COVID-19 will be with us through the remainder of 2020 and almost certainly beyond. New Zealand needs a viable strategy to protect its populace until a vaccine is developed and in wide use. Until that time, it makes sense to protect the population by putting in place treatments that will be safe and effective, such as the use of convalescent sera and the use of direct-acting anti-virals. These treatments should be sourced externally or made locally, but steps in this direction must now begin as the lockdown ends. New Zealand has the scientists, the facilities and the will to make this happen, but the support of the government and the population will be needed if this plan is to succeed.
\end{abstract}

$\mathrm{S}$ ince the beginning of 2020 the entire globe has experienced the inexorable spread of the SARS-CoV-2 virus and the resultant disease, COVID-19. ${ }^{1}$ At the time of this writing there are 2.1 million total cases worldwide resulting in 134,000 deaths with both of these figures felt to be underestimations of fact.

New Zealand with its prescient imposition of a country-wide lockdown has to date avoided the worst ravages of this illness, but even so, at the time of this writing there have been 1,386 cases and nine deaths reported. ${ }^{2}$ Analysis of the epidemic curves indicated that if this lockdown had not been imposed these numbers would have been much higher. And at the time of this writing, the lockdown is working and that it is hoped that active cases from the first phase of COVID-19 will be eliminated from the country. As a result, the government is now considering a move to Level 3 restrictions with mandatory quarantine at the border.
However, it is important to stress that the population of New Zealand as a whole is not immune to SARS-CoV-2 infection, and that a reintroduction of the virus in the future is a virtual certainty. Further it seems likely that this reintroduction will occur before the 12-24 months (or longer) required to produce and distribute an effective COVID-19 vaccine. In fact, low-level transmission may persist in New Zealand due to asymptomatic shedders that can shed virus post-infection for many days to several weeks.,4

In 1918 the world experienced a global pandemic with H1N1 influenza that led to worldwide infection of $30-40 \%$ of the population and up to 40 million deaths. ${ }^{5,6}$ There were three global phases to this pandemic; the first phase in June 1918 was severe with five deaths per 1,000 persons, but the second phase beginning in October 1918 caused 25 deaths per 1,000 persons at its peak and was thus five times more severe. The final phase, in March of 1919, peaked at 10 deaths 
per 1,000 persons. If SARS-CoV-2 behaves in a similar fashion, more phases of infection will come later this year and it is important to plan accordingly.

\section{Vaccine timeframe is long}

Fortunately, the successful lockdown has bought New Zealand time to prepare for a likely second wave of COVID-19. This means more time to perfect the use of rapid diagnostics and to expand pandemic medical capability. But it also means more time to prepare effective treatments for New Zealanders severely affected by COVID-19.

In an ideal scenario a vaccine would be in place before any resurgence of SARS-CoV-2 in New Zealand, but a vaccine will require at least 12-24 months to develop and test. Once tested, production would need to be scaled up and worldwide distribution carried out. Even if the hypothetical timetable for completion comes to fruition, New Zealand is not likely to be an early recipient. In fact, one attempt to reserve a promising vaccine candidate to one country has already been seen.

It is also possible that developing a vaccine on this accelerated timetable will not be successful. For example, some vaccine constructs utilised for coronaviruses have been found to lead to potentiation of infection, suggesting that careful assessment for vaccine safety, as always, will be needed. ${ }^{7,8}$ Over time it is anticipated that a successful SARS-CoV-2 vaccine will be produced, but a delay would not be surprising.

\section{Short-term acquisition of effective COVID-19 treatments}

While waiting on a SARS-CoV-2 vaccine to be developed, it would be prudent to put in place treatments for New Zealanders who might be severely affected by future outbreaks of SARS-CoV-2. Two treatments that are likely to be effective are convalescent sera and direct-acting anti-virals. Both could be acquired in the short term while a vaccine is still pending and both can be made in New Zealand if they are unavailable from external sources.

\section{Convalescent sera}

Convalescent sera, as the name implies, is sera from patients who have recovered from an infectious disease, in this case COVID-19. The use of convalescent sera to treat or prevent infectious diseases has been in place for over a century and has been applied to both bacterial diseases, eg, pneumococcal disease, and viral diseases, eg, measles, influenza and coronavirus (as discussed below) ${ }^{8}$ Prior to the antibiotic era, the use of immune sera was sometimes the only possible treatment.

Neutralising antibodies were found in many patients following infection by the SARS virus. ${ }^{8}$ This has proven to be the case as well following infection with SARSCoV-2. ${ }^{9}$ The results from early clinical use of convalescent sera in COVID-19 have been encouraging with pilot studies indicating that its use is both safe and effective. ${ }^{10}$ These studies involve small numbers and are not well controlled, but they are encouraging enough that one pharmaceutical company, Takeda, has been reported to be making preparations to develop this product for clinical use. ${ }^{8}$ However, this process will take many months.

Fortunately, New Zealand has in place all it needs to proceed with this therapy. There is a published assay to allow measurement of antibody potency. ${ }^{10}$ There is a screening pipeline in place to test sera for active infection, eg, SARS-CoV-2, HIV, Hepatitis B and C. And most importantly, there is a base of over 1,000 people from whom it may be possible to obtain sera. With the addition of a suitable clinical protocol, therapy with convalescent sera could be in place in a matter of months.

\section{Direct-acting anti-virals}

Direct-acting anti-virals (DAAV) are small molecule drugs that directly interfere with the replication of viruses. In the case of SARS-CoV-2, there are a large number of potential DAAV and they fall into three main families-polymerase inhibitors, protease inhibitors and other. ${ }^{11,12}$ The polymerase inhibitors targeting SARS-CoV-2 include some of the most promising options for treating COVID-19. The most notable members of this group are remdesivir and favipiravir, as well as galidesivir. ${ }^{13-17}$ These drugs work by blocking the viral RNA polymerase enzyme that allows the virus to replicate its nucleic acid coding strand. Both remdesivir and favipiravir have had some encouraging but mixed preliminary results in early clinical trials against SARSCoV-2, but important results of randomised 
controlled trials are due out soon. Galidesivir (BCX4430, Immucillin-A) is notable for being invented in New Zealand. ${ }^{16,17}$ BioCryst Pharmaceuticals is now recruiting patients for a clinical trial of this drug against COVID-19 patients in Brazil.

Protease inhibitors include drugs that block the main (3C-like) protease of SARSCoV-2 or that block other cellular proteases that are needed to process the coronavirus spike protein into a form that promotes viral uptake into human cells. ${ }^{11,18-22}$ Both of these protease actions are essential for viral replication and both are drug targets, but these proteases and their known inhibitors are very different.

During both the SARS and MERS outbreaks, it was discovered in uncontrolled case reports and series that Kaletra (lopinavir/ritonavir), a commonly used anti-HIV drug, seemed to help SARS infected patients by blocking the 3CL protease. ${ }^{23,24}$ Early data on its use for SARS-CoV-2 suggests only weak activity against COVID-19, but this data is from studies with small patient numbers. ${ }^{25}$ Data from other 3CL protease inhibitors against SARS-CoV-2 infection in humans is not yet available. Similarly, no human data is available for protease inhibitors that block spike protein processing. One such inhibitor, camostat mesylate, has been approved for use in humans for another condition, pancreatitis, therefore, if camostat were found to be effective against COVID-19 it could be rapidly pressed into clinical use. ${ }^{22}$

The final set of anti-viral drugs potentially available to treat COVID-19 fall into the 'other' category, and include agents like chloroquine, azithromycin, ivermectin and many others. ${ }^{11,14}$ Many of these drugs have already been approved for use in humans for non-viral diseases and they have mixed or no data from clinical studies in humans against COVID-19. ${ }^{26,27}$ As for all repurposed drugs, if they are found to be effective against SARS-CoV-2, they could be quickly drafted into use.

Data on these many drugs, some promising, some less so, has steadily emerged during the pandemic. Much more data will be coming out over the next few months, and it is likely that at least a few studies of COVID-19 treatments will be promising enough to provide a convincing argument for their clinical use in COVID-19 cases.

\section{Sourcing needed drugs for New Zealand}

The amount of anti-viral drug that New Zealand might require during the $1-2$ year (or longer) vaccine development period is subject to debate, but according to modelling completed for the Ministry of Health by the HEIRU, an uncontrolled outbreak in New Zealand could lead to between 92,500 to 124,000 hospitalisations with ICU admissions ranging from 14,400 to $19,200 .^{28}$ Given that the prospect of an uncontrolled outbreak is unlikely now but that smaller and more frequent outbreaks could occur over the period before a vaccine is available, a reasonable scale of anti-viral courses to target would be in the range of 5,000-10,000.

Historically, New Zealand has adopted a plan of sourcing new pharmaceutical treatments from the manufacturers after definitive clinical trials with clear demonstration of efficacy, and it would be prudent for New Zealand to stockpile one or two of these agents for use in any significant COVID-19 repeat outbreaks in New Zealand should they take place. However, it seems likely that, due to world-wide pressure on manufacturers to supply these drugs globally, New Zealand will be required to make its own anti-virals. New Zealand law has built into it strong protection for intellectual property except in the case of a national emergency in which the acquisition of material for the public good is essential. In such a scenario New Zealand law provides a mechanism whereby patented materials can be manufactured locally. Even in such a case, it is preferred that it be done with an agreement in place with the appropriate company and with reasonable compensation.

This issue aside, New Zealand has in place all that is needed to manufacture directacting anti-virals for COVID-19 infection. Several large medicinal chemistry groups with excellent track records in developing drugs for clinical trials are located throughout the country. New Zealand has a Good Manufacturing Practice (GMP) facility-GlycoSyn at Callaghan Innovation-that can be employed to generate 
and test the material needed to meet the anticipated needs outlined above. With Government support to facilitate the regulatory requirements for drug manufacture and distribution it will be feasible to generate pharmaceuticals in commercial form and quantity as therapeutics. New
Zealand has the companies with experience in compounding, formulating, packaging and sterilising pharmaceuticals for oral and parenteral administration. Once the decision is made as to which drugs are to be synthesised, this material could be in place in a matter of months.

\section{Competing interests:}

Dr Krause reports that the authors of this paper have submitted a grant application to the MBIE COVID Innovation Acceleration Fund (CIAF) in which they propose to do some of the things described within the manuscript. This application is pending. Drs Furneaux and Tyler are inventors on a patent family that had composition of matter claims on Galidesivir. This patent family was licensed to BioCryst Pharmaceuticals, Inc, but the term of this patent family has expired in respect of Galidesivir, and we have not received, nor are we due, any royalties related to sales of Galidesivir.

\section{Acknowledgements:}

The authors acknowledge Prof Paul Atkinson for helpful discussions and for sharing a draft of his plans for New Zealand post-lockdown. The authors would like to acknowledge their affiliation with the Maurice Wilkins Centre.

\section{Author information:}

Kurt L Krause, Department of Biochemistry, University of Otago; Richard Furneaux, Ferrier Research Institute, Victoria University of Wellington; Paul Benjes, GlycoSyn at Callaghan Innovation; Margaret Brimble, Chemical Sciences, University of Auckland;

Tony Davidson, GlycoSyn at Callaghan Innovation; William Denny, Auckland Cancer Society Research Centre, University of Auckland; Lawrence Harris, Ferrier Research Institute, Victoria University of Wellington; Simon Hinkley, Ferrier Research Institute, Victoria University of Wellington; Peter Tyler, Ferrier Research Institute, Victoria University of Wellington; James E Ussher, Department of Microbiology and Immunology, University of Otago; Vernon Ward, Department of Microbiology and Immunology, University of Otago.

\section{Corresponding author:}

Prof Kurt L Krause, Department of Biochemistry, University of Otago, Dunedin; Webster Centre for Infectious Diseases; Maurice Wilkins Centre.

kurt.krause@otago.ac.nz

URL:

www.nzma.org.nz/journal-articles/the-post-lockdown-period-should-be-used-to-acquireeffective-therapies-for-future-resurgence-in-sars-cov-2-infections

\section{REFERENCES:}

1. Li Q, et al. Early Transmission Dynamics in Wuhan, China, of Novel Coronavirus-Infected Pneumonia. The New England journal of medicine 2020; 382:1199-1207, doi:10.1056/ NEJMoa2001316.

2. Ministry of Health, COVID-19 (novel coronavirus), <http://www. health.govt.nz/our-work/ diseases-and-conditions/ covid-19-novel-coronavirus> (2020).

3. Lan L, Xu D, Ye G, Xia C, Wang S, Li Y, Xu H. Positive RT-PCR Test Results in Patients Recovered From COVID19. Jama, doi:10.1001/ jama.2020.2783 (2020).

4. Zhou F, et al. Clinical course and risk factors for mortality of adult inpatients with COVID19 in Wuhan, China: a retrospective cohort study. Lancet 2020; 395:1054-1062, doi:10.1016/ s0140-6736(20)30566-3.

5. Morens DM, Taubenberger JK. 1918 influenza, a puzzle with missing pieces. Emerg Infect Dis, 2012; 18:332-335, doi:10.3201/ eid1802.111409. 
6. Taubenberger JK, Morens DM. 1918 Influenza: the mother of all pandemics. Emerg Infect Dis, 2006; 12:15-22, doi:10.3201/ eid1201.050979.

7. Chen WH, Strych U, Hotez PJ, Bottazzi ME. The SARSCoV-2 Vaccine Pipeline: an Overview. Current tropical medicine reports, 2020:1-4, doi:10.1007/ s40475-020-00201-6.

8. Casadevall A, Pirofski LA. The convalescent sera option for containing COVID-19. J Clin Invest, 2020; 130:1545-1548, doi:10.1172/jci138003.

9. Wu F, et al. Neutralizing antibody responses to SARS-CoV-2 in a COVID19 recovered patient cohort and their implications. medRxiv, 2020.2003.2030.20047365, doi:10.1101/2020.03.30. 20047365 (2020).

10. Duan $\mathrm{K}$, et al. The feasibility of convalescent plasma therapy in severe COVID-19 patients: a pilot study. medRxiv, 2020.2003.2016. 20036145, doi:10.1101/ 2020.03.16.20036145 (2020).

11. Li G, De Clercq E. Therapeutic options for the 2019 novel coronavirus (2019nCoV). Nature reviews. Drug discovery, 2020; 19:149-150, doi:10.1038/ d41573-020-00016-0.

12. Santarpia JL, et al. Transmission Potential of SARS-CoV-2 in Viral Shedding Observed at the University of Nebraska Medical Center. medRxiv, 2020.2003.2023. 20039446, doi:10.1101/2020. 03.23.20039446 (2020).

13. Grein J, et al. Compassionate Use of Remdesivir for Patients with Severe Covid-19. The New England journal of medicine, doi:10.1056/ NEJMoa2007016 (2020).

14. Rosa SGV, Santos WC. Clinical trials on drug repositioning for COVID-19 treatment. Revista panamericana de salud publica $=$ Pan American journal of public health, 2020; 44:e40, doi:10.26633/rpsp.2020.40.

15. Wang M, et al. Remdesivir and chloroquine effectively inhibit the recently emerged novel coronavirus (2019-nCoV) in vitro. Cell Res, 2020; 30:269-271, doi:10.1038/ s41422-020-0282-0.

16. Julander JG, et al. BCX4430, a novel nucleoside analog, effectively treats yellow fever in a Hamster model. Antimicrob Agents Chemother; 2014; 58:6607-6614, doi:10.1128/aac.03368-14

17. Warren TK, et al. Protection against filovirus diseases by a novel broad-spectrum nucleoside analogue BCX4430. Nature, 2014; 508:402-405, doi:10.1038/nature13027.

18. Pedersen NC, et al. Efficacy of a 3C-like protease inhibitor in treating various forms of acquired feline infectious peritonitis. Journal of feline medicine and surgery, 2018; 20:378-392, doi:10.1177/1098 $612 \times 17729626$.

19. Vaduganathan $M$, et al. Renin-Angiotensin-Aldosterone System Inhibitors in Patients with Covid-19. The New England journal of medicine, doi:10.1056/ NEJMsr2005760 (2020).

20. Zhang L, et al. Crystal structure of SARS-CoV-2 main protease provides a basis for design of improved alpha-ketoamide inhibitors. Science, doi:10.1126/ science.abb3405 (2020).

21. Hoffmann M, Kleine-Weber H, Krüger N, Müller M, Drosten C, Pöhlmann S. The novel coronavirus 2019 (2019-nCoV) uses the SARS-coronavirus receptor ACE2 and the cellular protease TMPRSS2 for entry into target cells. bioRxiv,
2020.2001.2031.929042, doi:10.1101/2020.01.31. 929042 (2020).

22. Hoffmann M, et al. SARSCoV-2 Cell Entry Depends on ACE2 and TMPRSS2 and Is Blocked by a Clinically Proven Protease Inhibitor. Cell, doi:10.1016/j. cell.2020.02.052 (2020).

23. Kim UJ, Won EJ, Kee SJ, Jung SI, Jang HC. Combination therapy with lopinavir/ritonavir, ribavirin and interferon-alpha for Middle East respiratory syndrome. Antiviral therapy, 2016; 21:455-459, doi:10.3851/imp3002.

24. Chu CM, et al. Role of lopinavir/ritonavir in the treatment of SARS: initial virological and clinical findings. Thorax, 2004; 59:252-256, doi:10.1136/ thorax.2003.012658.

25. Cao B,et al. A Trial of Lopinavir-Ritonavir in Adults Hospitalized with Severe Covid-19. The New England journal of medicine, doi:10.1056/ NEJMoa2001282 (2020).

26. Chen Z, Hu J, Zhang Z, Jiang S, Han S, Yan D, Zhuang $\mathrm{R}, \mathrm{Hu} \mathrm{B}$, Zhang Z. Efficacy of hydroxychloroquine in patients with COVID-19: results of a randomized clinical trial. medRxiv, 2020.2003.2022. 20040758, doi:10.1101/2020 03.22.20040758 (2020)

27. Gautret P, et al. Hydroxychloroquine and azithromycin as a treatment of COVID-19: results of an open-label non-randomized clinical trial. Int J Antimicrob Agents, 105949, doi:10.1016/j.ijantimicag.2020.105949 (2020).

28. Wilson N, Baker M. Potential Age-Specific Health Impacts from Uncontrolled Spread of the COVID-19 Pandemic on the New Zealand Population Using the CovidSIM Model (Ministry of Health, 2020). 